\title{
MINERALOGY AND GENESIS OF MIXED-LAYER ILLITE-VERMICULITE IN THE HOMOGENEOUS RED SOIL AND THE NET-LIKE RED SOIL OF XUANCHENG, CHINA
}

\author{
YIN, K. ${ }^{1 *}-$ HONG, H. $^{1}-$ PAN, Y. $^{2}-$ LIU, Z. ${ }^{1}$ \\ ${ }^{1}$ Faculty of Earth Sciences, China University of Geosciences, Wuhan, Hubei 430074, China \\ ${ }_{2}^{2}$ State Key Laboratory of Geological Processes and Mineral Resources, China University of \\ Geosciences, Wuhan, Hubei 430074, China \\ *Corresponding author \\ e-mail: yinke1984@qq.com; tel: +86-027-13100719153 \\ (Received 24 $4^{\text {th }}$ Oct 2016; accepted $20^{\text {th }}$ Dec 2016)
}

\begin{abstract}
Mineralogy and genesis significance of mixed-layer illite-vermiculite in Xuancheng red soil section were investigated using X-ray diffraction (XRD), high resolution transmission electron microscopy (HRTEM), and inductively coupled plasma emission spectrum (ICP-AES). XRD shows that clay minerals in the red soils are composed of illite, vermiculite, mixed-layer illite-vermiculite, and kaolinite. The lattice fringes of mixed-layer illite-vermiculite were directly observed under HRTEM. Vermiculite layers were trapped within the illite layers, indicating that mixed-layer illite-vermiculite was derived from illite. The higher content of vermiculite, mixed-layer illite-vermiculite, and kaolinite in the net-like red soil relative to the homogeneous red soil suggested a warmer and more humid climate prevailing over the mid-Pleistocene and a relatively cool and dry climate prevailing over the late Pleistocene. A lower hydroxy-Al hydroxides content of the vermiculitic layers in the net-like red soil compared to those of the homogeneous red soil resulted in more tortuous lattice fringes. Hence, Mixed-layer illite-vermiculite with hydroxy-Al hydroxides interlacated is sensitive to the climatic environment change in soil-forming process.
\end{abstract}

Keywords: paleosoil; climate change;soil genesis; paleoecology; Pleistocene

\section{Introduction}

As the ultimate weathering products of the paleosoil, the formation and development of clay minerals are mainly controlled by climate and geological conditions (Deepthy and Balakrishnan, 2005; Merriman, 2002; Singer, 1984). Therefore, the paleoclimate information is well preserved in the clay mineral compositions (Singer, 1980; 1984). With the popularity of the research on global changes, the indicative function of clay minerals on paleoclimate has attracted great attention. The application of the climate and environment information records documented in paleosoil has become a hot spot for the earth sciences (Nedachi et al., 2005; Sedov et al., 2003). The assemblage, relative content and crystallinity of clay minerals in paleosoil have been widely used in the reconstruction of the paleoclimate(Das et al., 2013; Fonseca et al., 2007; Hong et al., 2009; Ji et al., 2002; Liu et al., 2003; Xie et al., 2013; Zajzon et al., 2012). The clay minerals of mixed-layer clay minerals formed in the relatively narrow climate conditions are quite sensitive to the climate changes. Hong et al. (2012) has investigated the content variations 
of mixed-layer kaolinite-smectite in the mid-lower reaches of the Yangtze River and come to a conclusion that the climate in Jiujiang gradually has evolved to being relatively dry and cold since the Middle Pleistocene (Hong et al., 2012). Doval et al. (2012) found that both mixed-layer chlorite-smectite and illite-smectite were present in weathering profile in central Spain and pointed out that the two mixed-layer clay minerals would be further transformed into smectite or kaolinite under a more warm and humid environment (Doval et al., 2012). It is obviously that the research into the unique mixed-layer clay minerals in paleosoil is conductive to revealing the climate and environment information during their formation and understanding major climate changes, geological events and processes in the past.

The mid-lower reaches of the Yangtze River is located on the edge of the southern part of the monsoon intersection area, and belongs to sensitive region to climate changes (Zhu, 2007). The results of Quaternary Research show that the red clay deposits extensively distributed in South China was formed in the Pleistocene (Xiong et al., 2002; Zhao and Yang, 1995). The sedimentary cycles of red soil shows a good comparison with the Loess-paleosoil sequence in the north China, which can serve as a perfect carrier for the reconstruction of the Quaternary climate (Zhao and Yang, 1995). However, due to the lacking of fossils in the red soil sediments, as well as the transformation of magnetic minerals and the strong leaching and migration of elements in red soils led by the intense chemical weathering, the geochemistry and paleontology are tremendously limited. In particular, magnetostratigraphy widely used in the study of the loess deposits in north China is no longer suitable for red soil in south China (Yang et al., 2008). Therefore, the existing research on the climatic and environmental information of the red soil in South China is still deficient. Obviously, the unique sensitivity of mixed-layer illite-vermiculite to climate change can undoubtedly make up for the deficiency of the traditional research methods in the study of the red soil sediments, which is also conductive to understand the response of South China to global climate change since Quaternary. However, the existing research on mixed-layer illite-vermiculite in paleosoil is scarce. For example, the studies on identification, fine structure and genesis of mixed-layer illite-vermiculite are defiant, which limits its application in revealing the paleoclimatic evolution. Mixed-layer illite-vermiculite is widely developed in Xuancheng red soil section of the mid-lower reaches of the Yangtze River area. X-ray powder diffraction (XRD), high resolution transmission electron microscopy analysis (HRTEM), and inductively coupled plasma emission spectrometry (ICP-AES) are employed to investigate the mineralogy of mixed-layer illite-vermiculite, with the expect to provide detailed scientific data for studying paleoclimatology of the mixed-layer clay minerals.

\section{Materials and methods}

\section{Experimental materials}

Xuancheng is located in the southeast of Anhui Province (Fig.l) in China, and the landform is characterized by low mountains and hills, intermountain basin and 
interchannel plain. The Xuancheng section is located near Xiangyang village brickworks $\left(118^{\circ} 51^{\prime} \mathrm{E}\right.$ and $30^{\circ} 54^{\prime} \mathrm{N}$,): It is in the south of Shuiyangjiang River in the lower reaches of the Yangtze River, and on the second terrace. The altitude of the section ranges from 20 to $45 \mathrm{~m}$ above the sea level from the bottom to the top. Homogeneous red soil and net-like red soil are both well preserved. The upper homogeneous red soil is about $2.2 \mathrm{~m}$, and the lower net-like red soil is about $8.2 \mathrm{~m}$. Thermoluminescence dating result at $\sim 0.8 \mathrm{~m}$ of Xuancheng laterite section is $41( \pm 5) \mathrm{ka}$. The electron spin resonance results at $\sim 2.4$ $\mathrm{m}, \sim 4.0 \mathrm{~m}, \sim 7.9 \mathrm{~m}$ and $\sim 9.9 \mathrm{~m}$ are $>110 \mathrm{ka}, 274( \pm 27) \mathrm{ka}, 436( \pm 43) \mathrm{ka}$ and $588( \pm 58) \mathrm{ka}$, respectively (Hong et al., 2010). The above results show that the formation of the Xuancheng section is consistent with the Jiujiang section, both of which are the weathering products since the Middle Pleistocene. two representative samples from homogeneous red soil and net-like red soil are selected to carry out a comparative study, the depth of which are $0.65 \mathrm{~m}$ (XC-013) and $5.15 \mathrm{~m}$ ( XC-103), respectively.

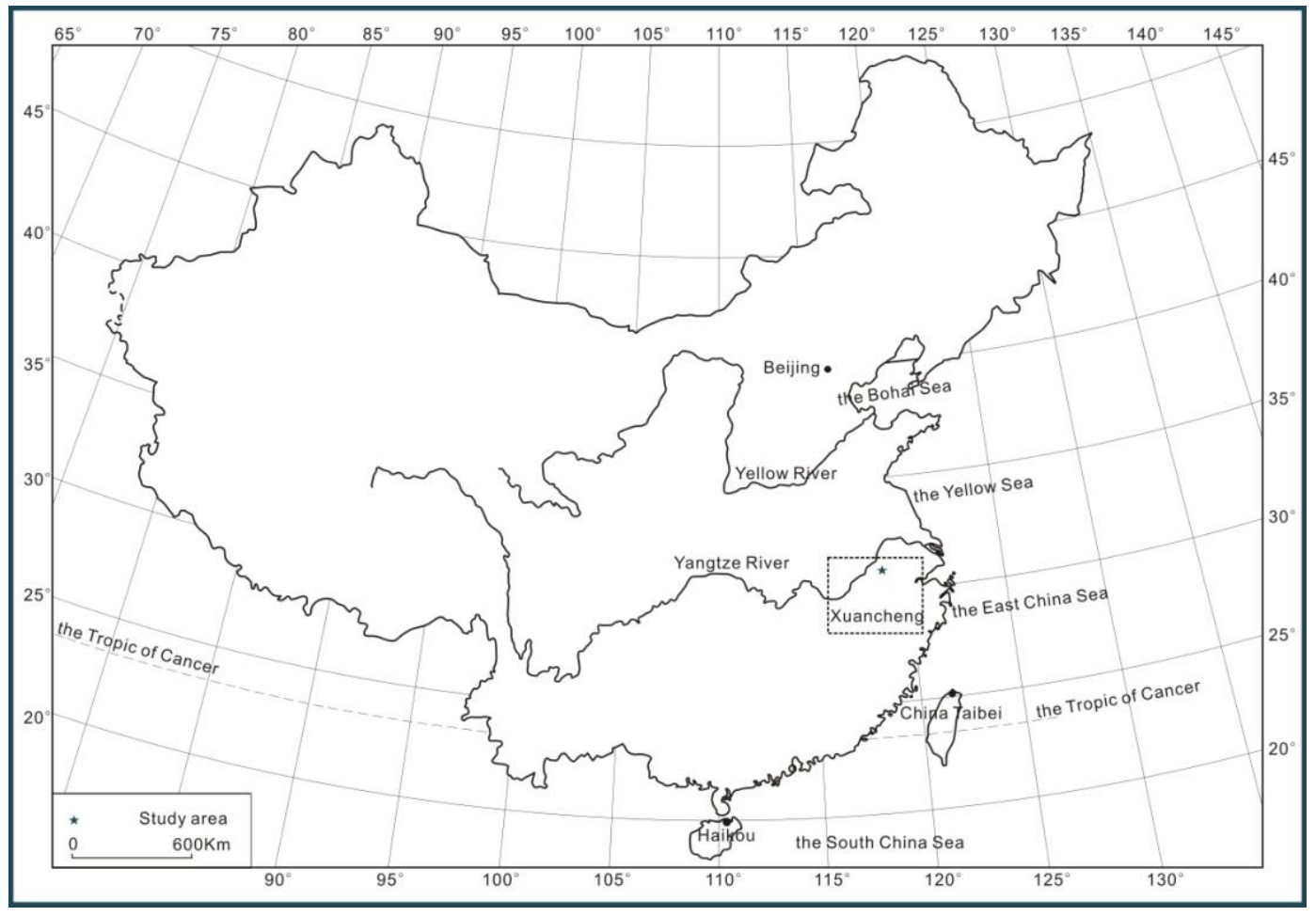

Figure 1. A generalized map showing the location of the study area

\section{Experimental method}

\section{$X$-ray diffraction}

First, the selected bulk samples were put into the oven at a constant temperature of 60 ${ }^{\circ} \mathrm{C}$ for 24 hours. The dried sample were grinded to passing through $200^{\#}$ sieve. $\sim 20 \mathrm{~g}$ sieved samples were pretreated with $30 \% \mathrm{H}_{2} \mathrm{O}_{2}$ overnight to remove organic materials. Then, The clay mineral fraction $(<2 \mu \mathrm{m})$ was obtained by sedimentation and centrifugation(Brown and Brindley, 1980). Thus the clay mineral sample of higher purity 
could be obtained. The diffraction analysis of the clay minerals were prepared with the oriented air-dried samples (Air), Mg-saturated samples ( $\mathrm{Mg}$-air), Mg-saturated and glycerol-solvated samples ( Mg-gly), Mg-saturated and $400^{\circ} \mathrm{C}$ heated samples (Mg-400), and $\mathrm{Mg}$-saturated and $600{ }^{\circ} \mathrm{C}$ heated samples $(\mathrm{Mg}-600)$. The detailed preparation processes of various orientation samples are as follows: the oriented air-dried samples are obtained by directly dry the clay mineral fraction in the air; the $\mathrm{Mg}$-saturated samples are obtained by soaking the clay mineral fraction in the $1 \mathrm{~mol} / \mathrm{L} \mathrm{MgCl}_{2}$ solution at a constant temperature of $50^{\circ} \mathrm{C}$; the $\mathrm{Mg}$-saturated and glycerol-solvated samples are obtained by applying $10 \%$ glycerol solutions to the oriented air-dried samples; $400^{\circ} \mathrm{C}$ heated samples and $600{ }^{\circ} \mathrm{C}$ heated samples are obtained by heating the $\mathrm{Mg}$-saturated samples to $400^{\circ} \mathrm{C}$ and $600{ }^{\circ} \mathrm{C}$ in the furnace for 2 hours, respectively. The X-ray diffraction analysis of the above oriented clay samples were carried out on Panalytical X'Pert PRO DY2198 diffractometer at the Laboratory of Geological Process and Mineral Resources, China University of Geosciences (Wuhan), which was operated at $40 \mathrm{kV}$ and $40 \mathrm{~mA}$ with $\mathrm{Ni}$-filtered $\mathrm{Cu} \mathrm{K} \alpha$ radiation. It was measured from $3^{\circ}$ to $35^{\circ} 2 \theta$ at a scan rate of $4^{\circ} 2 \theta / \mathrm{min}$ and a step size of $0.02^{\circ} 2 \theta$.

\section{HRTEM analysis}

The air-dried clay sample was embedded in M-bond 610 resin between two Si wafers, and then the embedded sample was solidified in an electric oven at $80^{\circ} \mathrm{C}$ for $2 \mathrm{~h}$, to ensure preferential orientation of the (001) planes of clay minerals. This resin was used to prevent damages to clay minerals in the process of ion milling and HRTEM observations. The thin section was obtained by cutting the Si wafers and grinding the Si wafers to slices of less than $0.5 \mathrm{~mm}$ vertically. It was then stuck to a copper ring for thinning by argon ion using a Gatan Model 691PIPS precision ion polishing system. HRTEM observations were performed on a Philips CM12 high resolution transmission electron microscope equipped with an EDAX9100 X-ray energy dispersive detector (EDS): The instrument was operated at an accelerating voltage of $120 \mathrm{kV}$ and a beam current of $\sim 20 \mathrm{~A}$, with a point resolution of $0.34 \mathrm{~nm}$ and line resolution of $0.20 \mathrm{~nm}$. In order to obtain the best contrast effect of the mixed-layer clay minerals, the lattice fringe images were obtained under over-focus conditions (Guthrie and Veblen, 1989), following slight adjustments in tilting of (001) layers relative to the electron beam. The EDS analysis was undertaken in TEM mode only after taking the lattice-fringe images. Analyses were carried out using a square raster $1000 \AA$ A-wide to minimize diffusion of alkali ions (Buatier et al., 1992).

\section{Inductively coupled plasma atomic emission spectrometry}

In order to determine the principal cations in interlayer exchange sites of the clay minerals, an extraction experiment was undertaken using a $1 \mathrm{M} \mathrm{KCl}$ solution(Barre and Velde, 2010). $30 \mathrm{mg}$ of the clay fraction was treated with $25 \mathrm{ml} 1 \mathrm{M} \mathrm{KCl}$ solution at $80^{\circ} \mathrm{C}$ for 12 hours in a sealed polyethylene tube. The extracted solution was then separated from the clay fraction residue by centrifuging for 30 minutes and the supernatant was transferred into a $10 \mathrm{ml}$ sealed polyethylene tube. The concentrations of $\mathrm{Al}$ and/or $\mathrm{Mg}$, 
$\mathrm{Ca}, \mathrm{Na}$ and $\mathrm{Fe}$ in the supernatant were measured using an inductively coupled plasma atomic emission spectrometer (ICP-AES).

\section{Results and discussion}

\section{$X$-ray diffraction characteristics of mixed-layer illite-vermiculite}

XRD analysis results showed that the clay minerals in Xuancheng section were mainly composed of illite, vermiculite, kaolinite and mixed-layer illite-vermiculite (Fig.2a, b): The diffraction peaks of $10.0 \AA, 5.0 \AA$ and $3.33 \AA$ are characteristic diffraction peaks of illite. $14.2 \AA$ is the (001) diffraction peak of vermiculite, and glycerol treatment does not alter the peak. However, the $14.2 \AA$ diffraction peak disappeared after heating to $400{ }^{\circ} \mathrm{C}$. An obvious "tail" phenomenon occurs on the left of $10.0 \AA$ diffraction peak. This proves that there is a certain amount of hydroxyl components in the interlayer of vermiculite (Harris et al., 1992; Meunier, 2007). The "tail" phenomenon on the left of $10.0 \AA$ diffraction peak disappeared after heating to $600{ }^{\circ} \mathrm{C}$. This proves that the hydroxyl components in interlayer of vermiculite were destroyed. The $7.13 \AA$ and $3.57 \AA$ diffraction peaks still existed after heating to $400{ }^{\circ} \mathrm{C}$, and disappeared on the heating to $600^{\circ} \mathrm{C}$. This indicated that there was kaolinite in samples. Diffraction peaks between 10 14 $\AA$ were the characteristic peaks of mixed-layer illite-vermiculite. The peaks remained unchanged after glycerol saturation, and they disappeared after heating to 400 ${ }^{\circ} \mathrm{C}$. The diffraction peaks of mixed-layer illite-vermiculite were totally different in homogeneous red soil and net-like red soil: The diffraction peaks of mixed-layer illite-vermiculite in homogeneous red soil were not obvious on the air-dried sample. However, an obvious $12.1 \AA$ diffraction peak occurred after $\mathrm{Mg}$ saturation. The diffraction peak of mixed-layer illite-vermiculite of net-like red soil was presented as a wide and slow platform on the air-dried sample. This proves that there are mixed-layer illite-vermiculite minerals of different mixed-layer ratios in the sample. The 10-14 $\AA$ diffraction peak of mixed-layer illite-vermiculite as well as the $14.2 \AA$ diffraction peak of vermiculite were significantly enhanced after glycerol solvation.

The contents of illite, kaolinite, vermiculite and mixed-layer illite-vermiculite were measured through glycerol-solvated samples. The integral areas of peaks of $14.2 \AA$, 12 13 $\AA, 10.0 \AA$ and $7.16 \AA$ were selected to obtain clay contents, and the weight factors were 1.0, 0.33, 0.33, and 0.5 (Bengtsson and Stevens, 1998). Although the clay mineral assemblages of homogeneous red soil and net-like soil were basically the same, the contents of clay minerals were slightly different. The content results showed that the content of clay minerals in the homogeneous red soil was: $58 \%$ illite, $11 \%$ kaolinite, $16 \%$ vermiculite and $15 \%$ mixed-layer illite-vermiculite. The contents of various clay minerals in the net-like red soil were: $46 \%$ illite, $13 \%$ kaolinite, $22 \%$ vermiculite and $19 \%$ mixed-layer illite-vermiculite The content of kaolinite, vermiculite, and mixed-layer illite-vermiculite in net-like red soil is higher than that of homogeneous red soil, whereas the content of illite is lower than that of homogeneous red soil. The difference of clay mineral content was mainly caused by the different weathering intensity during the 
formation period. This proves that homogeneous red soil and net-like soil were formed in different pedogenic environments.
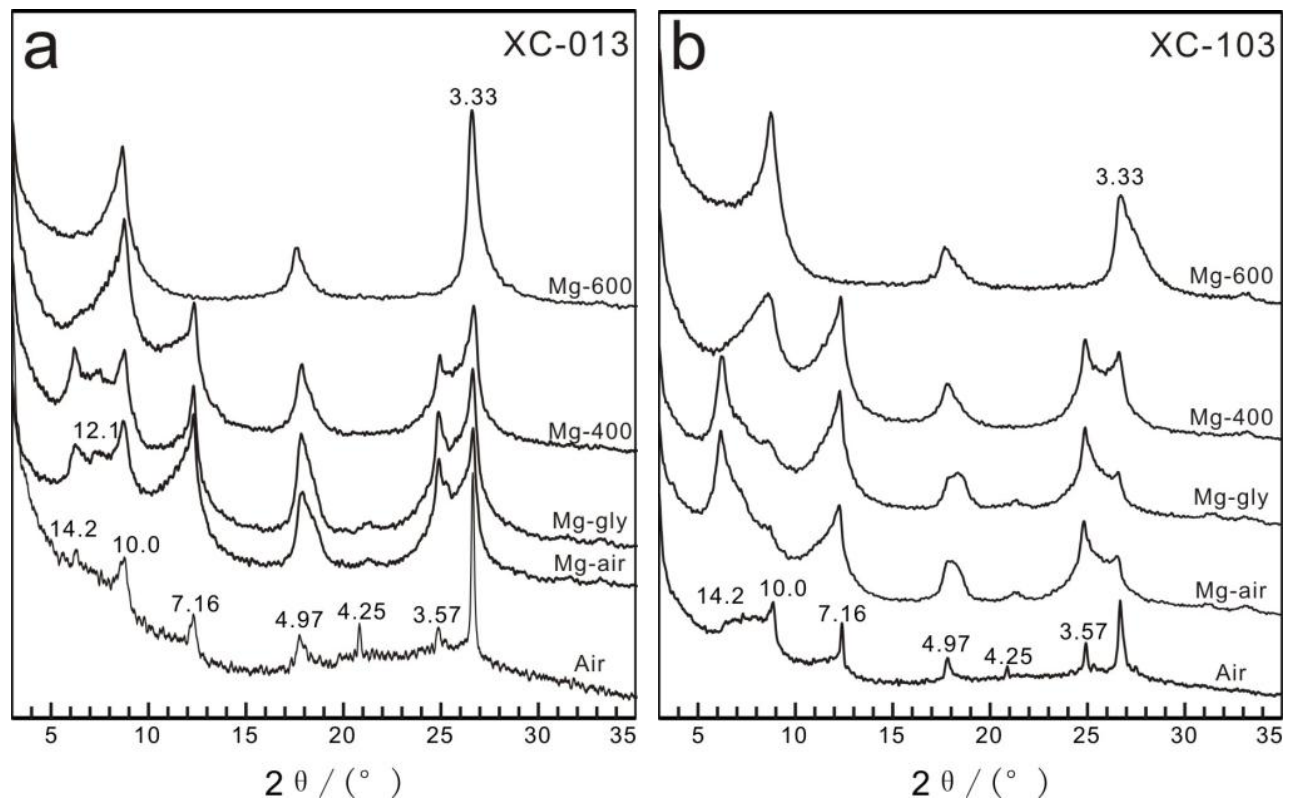

Figure 2. The XRD patterns of representative samples of red soils in the Xuancheng section ( $a$, a representative sample in the homogeneous red soil; $b$, a representative sample in the net-like red soil). Air-Air-dried;Mg-air-Mg-saturated at $25^{\circ} \mathrm{C} ; \mathrm{Mg}$-gly-Mg-saturated and glycerol solvation; $\mathrm{Mg}-400$ - Mg-saturated and heated to $400{ }^{\circ} \mathrm{C} ; \mathrm{Mg}$-600-Mg-saturated and heated to $600{ }^{\circ} \mathrm{C}$.

\section{Lattice fringe characteristics of mixed-layer illite-vermiculite}

Mixed-layer illite-vermiculites could be directly observed under HRTEM. It is commom that both illite layers and vermiculite layers occur within the same crystal grain (Fig.3a, b): The fringes of illite layers were relatively straight and the lattice-fringe spacings were about $10 \AA$. However, the fringes of vermiculite layers were curving, and the lattice-fringe spacings were between $10 \sim 14 \AA$ (Fig.3a, b): The 10 14 $\AA$ lattice-fringe spacings likely resulted from the dehydration of the $14 \AA$ lattice-fringe spacings under the electron beam (Vali and Hesse, 1992). No matters in homogeneous red soil samples or net-like red soil samples, vermiculite layers were entrapped within illite layers. This suggests that mixed-layer illite-vermiculite might be derived from illite. The incomplete transformation from illite to vermiculite led to the formation of mixed-layer illite-vermiculite. Vermiculite is usually formed in the relatively warm climate from illite under the environment of $\mathrm{PH}<6$. When illite is incompletely transformed to vermiculite, mixed-layer illite-vermiculite might be formed (Lin et al., 2002). Compared to homogeneous red soil samples, the clay mineral layers net-like red soil samples were more significantly tortuous (Fig.3a, b): This indicates that net-like red soils might be formed under more intense weathering, which resulted in the distortion of crystal lattice in the clay minerals. 

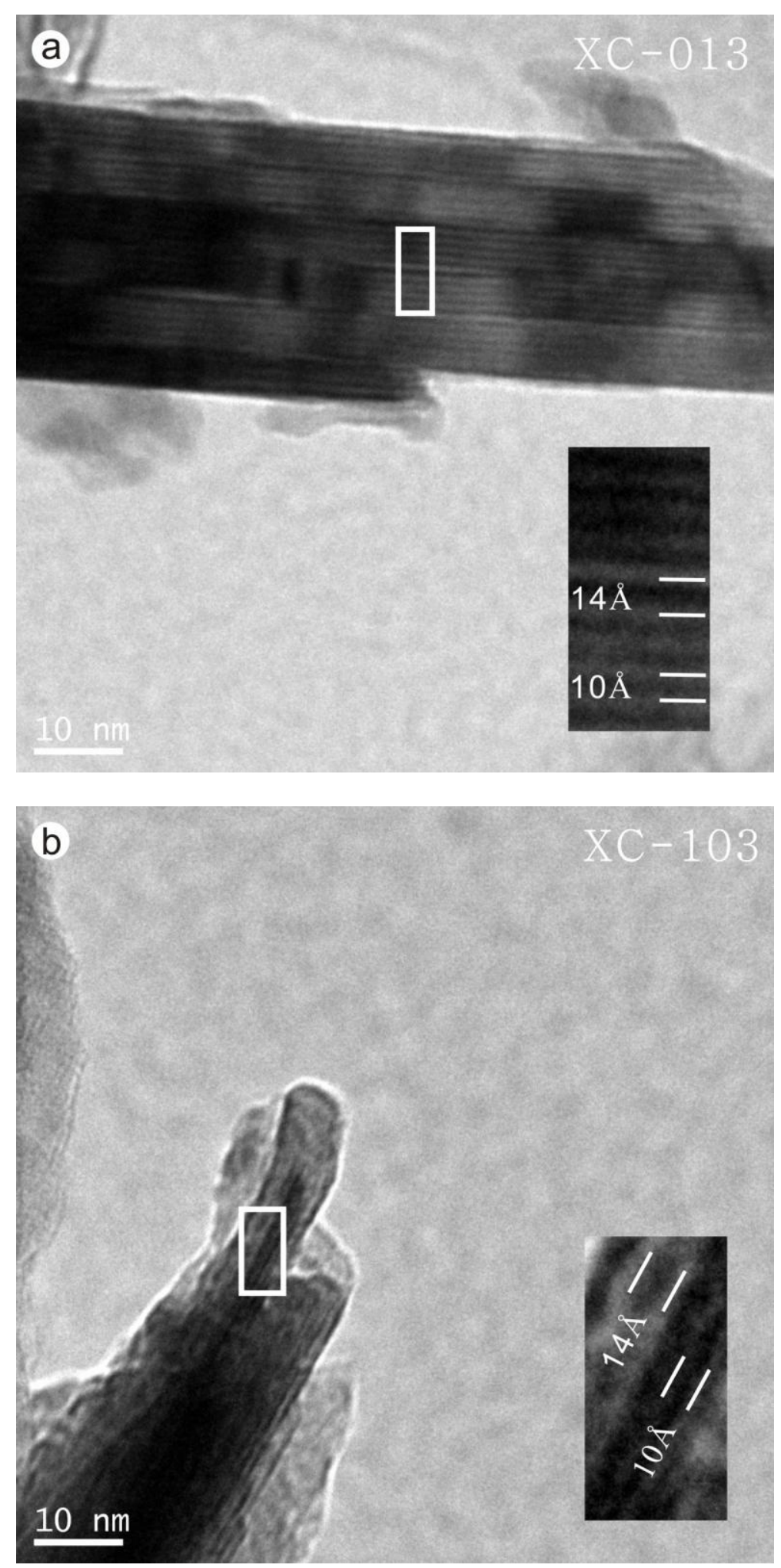

Figure 3. HRTEM images of mixed-layer illite-vermiculite of representative samples in Xuancheng red soils(a, mixed-layer illite-vermiculite in the homogeneous red soil; $b$, mixed-layer illite-vermiculite in the net-like red soil) 


\section{Cation exchange capacity of clay minerals in red soils}

ICP-AES results show that $\mathrm{Na}, \mathrm{Ca}, \mathrm{Mg}, \mathrm{Al}$ and $\mathrm{Fe}$ were present in the $\mathrm{KCl}$ extracts(Table 1): Extracted $\mathrm{Na}$ of clay minerals in homogeneous red soil was 43.7 $\mathrm{cmol}(+) / \mathrm{kg}, \mathrm{Mg}$ was $1.8 \mathrm{cmol}(+) / \mathrm{kg}, \mathrm{Ca}$ was $6.1 \mathrm{cmol}(+) / \mathrm{kg}$, Al was 0.8 $\mathrm{cmol}(+) / \mathrm{kg}, \mathrm{Fe}$ was $0 \mathrm{cmol}(+) / \mathrm{kg}$, and total extracted cations were 52.4 $\mathrm{cmol}(+) / \mathrm{kg}$. Extracted $\mathrm{Na}$ of clay minerals in net-like red soil was $80.0 \mathrm{cmol}(+) / \mathrm{kg}$, $\mathrm{Mg}$ was $3.2 \mathrm{cmol}(+) / \mathrm{kg}$, Ca was $12.8 \mathrm{cmol}(+) / \mathrm{kg}$, Al was $0.6 \mathrm{cmol}(+) / \mathrm{kg}$, Fe was $0.2 \mathrm{cmol}(+) / \mathrm{kg}$, and total extracted cations were $96.7 \mathrm{cmol}(+) / \mathrm{kg}$. The total extracted cations of the net-like red soil were larger than those of homogeneous red soil. The cations exchanged by $\mathrm{KCl}$ were mainly derived from the interlayer of clay minerals. Generally, $\mathrm{Na}$ and $\mathrm{Ca}$ are simple exchangeable ions, and $\mathrm{Mg}, \mathrm{Al}$, and Fe usually occur as polymerization ions in the interlayer region (Meunier, 2007). However, hydroxy-Fe and hydroxyl- $\mathrm{Mg}$ interlays are usually formed in reducing conditions and alkaline conditions, whereas hydroxy-Al appears to be the principal interlayers in acidic soils (Rich, 1968).

Table 1. Cation exchange capacity of clay minerals in Xuancheng red soils

\begin{tabular}{|c|c|c|c|c|c|c|}
\hline \multirow[t]{3}{*}{ Sample name } & \multicolumn{5}{|c|}{ Exchange cations } & \multirow{3}{*}{$\begin{array}{l}\text { Total cation exchange } \\
\text { capacity }(\mathrm{cmol}(+) \\
/ \mathrm{kg})\end{array}$} \\
\hline & \multicolumn{5}{|c|}{$(\mathrm{cmol}(+) / \mathrm{kg})$} & \\
\hline & $\mathrm{Al}$ & $\mathrm{Mg}$ & $\mathrm{Ca}$ & $\mathrm{Na}$ & $\mathrm{Fe}$ & \\
\hline XC-013 & 0.8 & 1.8 & 6.1 & 43.7 & 0 & 52.4 \\
\hline XC-103 & 0.6 & 3.2 & 12.8 & 80.0 & 0.2 & 96.7 \\
\hline
\end{tabular}

\section{Results and discussion}

Vermiculite and mixed-layer illite-vermiculite were ubiquitous in Xuancheng red soils. This indicated that the pedogenetic condition of the red soils was acidic, which was consistent with the PH value measurement results in Zhejiang, Hunan, Jiujiang Jiangxi (Zhu, 2007). Mixed-layer illite-vermiculite was also discovered in some ancient sediments, and it was considered as the clay mineral related with the diagenesis(Chamley and Debrabant, 1989). In acidic soil of New Zealand and Scotland, mixed-layer illite-vermiculite is considered to be the weathering product of dioctahedral mica (Bain et al., 1990; Churchman, 1980). Mixed-layer illite-vermiculite in Taiwan was originated from the weathering of illite (Lin et al., 2002). Therefore, the occurrence of mixed-layer illite-vermiculite indicated that the weathering was intensified. The increasing content suggests a warmer and more humid climate prevailing in that period. However, the 
research on genesis of mixed-layer illite-vermiculite was all based on the X-ray diffraction data. Direct evidences of genesis of mixed-layer illite-vermiculite were deficient (Bonifacio et al., 2009; Harris et al., 1992; Środoń, 1999). The technical difficulty in characterizing mixed-layer illite-vermiculite lies in the inability to separate them from the natural mixture of clay minerals in soils. High resolution transmission electron microscopy (HRTEM) microanalysis provides a chance to make direct microscopic observation on mixed-layer illite-vermiculite.

XRD analysis results show that the clay assemblages of the homogeneous red soil and the net-like red soil are basically the same, which are mainly illite, vermiculite, kaolinite and mixed-layer illite-vermiculite. The content of vermiculite, kaolinite and mixed-layer illite-vermiculite in the net-like red soil are higher than that of the homogeneous red soil, whereas its illite content is lower than that of the homogeneous red soil. $\mathrm{Na}, \mathrm{Ca}, \mathrm{Mg}, \mathrm{Al}$ and $\mathrm{Fe}$ were detected in the $\mathrm{KCl}$ extracts by ICP-AES, indicating that they are the main interlayer cations in the clay minerals. The red soils in south China are formed in acidic conditions (Zhu, 2007). Therefore, $\mathrm{Na}, \mathrm{Ca}, \mathrm{Mg}$ and $\mathrm{Fe}$ usually occur as simple exchangeable ions in the interlayer of clay minerals, whereas the intercalated $\mathrm{Al}$ is probably present as hydroxy-Al hydroxides in the interlayer of clay minerals in the Xuancheng red soils. More exactly, hydroxy-Al hydroxides usually occupy in the vermiculite or vermiculite layers of mixed-layers clays in acidic red soils. Hydroxy-interlayered vermiculite has been commonly reported in soil sediments (Bertrand et al., 2008; Huang et al., 2011; Shaw et al., 2010; Toksoy-Koksal et al., 2001). It is usually formed by the adsorption of hydroxide polymers into the interlayer region (Meunier, 2007), which would alter expansion and collapse of hydroxy-interlayered clay minerals(Dixon, 1961). Under HRTEM, the lattice fringes of clay minerals in the net-like red soil are more torturous than those of the homogeneous red soil, which results from a lower hydroxy-Al hydroxides content of the vermiculitic layers in the net-like red soil compared to those of the homogeneous red soil. This also suggests that the net-like red soil was formed in climatic environment with more intense weathering. It could be also observed under HRTEM that the vermiculite layers were entrapped within illite layers. This indicates that mixed-layer illite-vermiculite might be derived from illite. With the intensification of weathering, illite was transformed into mixed-layer illite-vermiculite, and finally formed into vermiculite with weathering proceeding (Yin et al., 2013).

Vermiculite is a clay mineral species with expansibility, and its adsorption and exchange capacity are higher than those of illite and kaolinite. Due to the higher content of vermiculite and mixed-layer illite-vermiculite of the net-like red soil, its cation capacity of clay minerals was higher than that of the homogeneous red soil. The lower net-like red soil and the upper homogeneous red soil respectively formed in the mid-Pleistocene and the late Pleistocene. The lower illite content and the higher contents of kaolinite, vermiculite and mixed-layer illite-vermiculite in the lower net-like red soil suggest relatively intense chemical weathering, and thus warmer and more humid climatic conditions in the mid-Pleistocene. In contrast, the higher illite content and the lower content of kaolinite, vermiculite and mixed-layer illite-vermiculite in the upper portion reveal relatively weak chemical weathering, and hence relatively cool and dry 
climates in the Late Pleistocene. A higher content of hydroxy-Al hydroxides were adsorbed in the interlayer of vermiculite and mixed-layer illite-vermiculite under weak chemical weathering, and the hydroxy-Al interlayers content decreased when weathering intensified. Therefore, mixed-layer illite-vermiculite in acidic red soils of Xuancheng, commonly hydroxy-Al hydroxides intercalated, is sensitive to the climatic environment change in soil-forming process. Therefore, study on the accurate identification and genesis of mixed-layer illite-vermiculite is of great scientific significance to reveal the climatic changes in soil forming process.

Acknowledgements. This work was supported by the Natural Science Foundation of China (41402036, 41272053 and 41472041), College Students' Self-innovation Project(1610491A09), Postdoctoral Science Foundation of China (2014M562084): The authors wish to thank Dr. Y. S. Gu for the sample preparation, Dr. X. W. Liu for the HRTEM observation, and Yu J. S. for the XRD analyses.

\section{REFERENCES}

[1] Bain, D.C., Mellor, A., Wilson, M.J. (1990): Nature and origin of an aluminous vermiculitic weathering product in acid soils from upland catchments in Scotland. - Clay Minerals 25: 467-475.

[2] Barre, P., Velde, B. (2010): Clays Developed Under Sequoia Gigantia and Prairie Soils: 150 Years of Soil-Plant Interaction in the Parks of French Chateaux. - Clays and Clay Minerals 58: 803-812.

[3] Bengtsson, H., Stevens, R.L. (1998): Source and grain-size influences upon the clay mineral distribution in the Skagerrak and northern Kattegat. - Clay Minerals 33: 3-13.

[4] Bertrand, S., Charlet, F., Charlier, B., Renson, V., Fagel, N. (2008): Climate variability of southern Chile since the Last Glacial Maximum: a continuous sedimentological record from Lago Puyehue (40 S). - Journal of Paleolimnology 39: 179-195.

[5] Bonifacio, E., Falsone, G., Simonov, G., Sokolova, T., Tolpeshta, I. (2009): Pedogenic processes and clay transformations in bisequal soils of the Southern Taiga zone. Geoderma 149: 66-75.

[6] Brown, G., Brindley, G.W. (1980): X-ray diffraction procedures for clay mineral identification. - In: Brindley, G. W., Brown, G. (eds.) Crystal Structures of Clay Minerals and Their X-Ray Identification., vol. 5. London: Mineralogical Society, pp. 305-359.

[7] Buatier, M.D., Peacor, D.R., O Neil, J.R. (1992): Smectite-illite transition in Barbados accretionary wedge sediments: TEM and AEM evidence for dissolution/crystallization at low temperature. - Clays and Clay Minerals 40: 65-80.

[8] Chamley, H., Debrabant, P. (1989): Diagenèse d'enfouissement et diagenèse thermique. Effets surles silicates argileux. - C.R. Acad. Sci. Paris 308: 389-394.

[9] Churchman, G.J. (1980): Clay minerals formed from micas and chlorites in some New Zealand soils. - Clay Minerals 15: 59-76.

[10] Das, S.S., Rai, A.K., Akaram, V., Verma, D., Pandey, A.C., Dutta, K., Prasad, G.R. (2013): Paleoenvironmental significance of clay mineral assemblages in the southeastern Arabian Sea during last 30 kyr. - Journal of Earth System Science 122: 173-185.

[11] Deepthy, R., Balakrishnan, S. (2005): Climatic control on clay mineral formation: Evidence from weathering profiles developed on either side of the Western Ghats. Journal of Earth System Science 114: 545-556.

[12] Dixon, J.B. (1961): Properties of Intergradient Chlorite-Expansible Layer Silicates of Soils. - Soil Science Society of America Journal 26: 358. 
[13] Doval, M., Martín-García, R., La Iglesia, Á., Alonso-Zarza, A.M. (2012): Clay minerals associations in palaeoweathering profiles from Central Spain: genesis and implications. Clay Minerals 47: 117-129.

[14] Fonseca, R., Barriga, F., Tazaki, K. (2007): Land erosion and associated evolution of clay minerals assemblages from soils to artificial lakes in two distinct climate regimes in Portugal and Brazil. - Clay Minerals 42: 161-179.

[15] Guthrie, G.D., Veblen, D.R. (1989): High-resolution transmission electron microscopy of mixed-layer illite/smectite: Computer simulations. - Clays and Clay Minerals 37: 1-11.

[16] Harris, W.G., Hollien, K.A., Bates, S.R., Acree, W.A. (1992): Dehydration of hydroxy-interlayered vermiculite as a function of time and temperature. - Clays and Clay Minerals 40: 335-340.

[17] Harris, W.G., Morrone, A.A., Coleman, S.E. (1992): Occluded mica in hydroxy-interlayered vermiculite grains from a highly-weathered soil. - Clays and Clay Minerals 40: 32-39.

[18] Hong, H., Churchman, G.J., Gu, Y., Yin, K., Wang, C. (2012): Kaolinite-smectite mixed-layer clays in the Jiujiang red soils and their climate significance. - Geoderma 173-174:75-83.

[19] Hong, H., Gu, Y., Li, R., Zhang, K., Li, Z. (2009): Clay mineralogy and geochemistry and their palaeoclimatic interpretation of the Pleistocene deposits in the Xuancheng section, southern China. - Journal of Quaternary Science 25: 662-674.

[20] Hong, H., Gu, Y., Yin, K., Zhang, K., Li, Z. (2010): Red soils with white net-like veins and their climate significance in south China. - Geoderma 160: 197-207.

[21] Huang, C., Zhao, W., Liu, F., Tan, W., Koopal, L.K. (2011): Environmental significance of mineral weathering and pedogenesis of loess on the southernmost Loess Plateau, China. - Geoderma 163: 219-226.

[22] Ji, J., Chen, J., Xu, H., Chen, T. (2002): Chemical weathering of chlorite in the Chinese loess - paleosol stratigraphy and climate change. - Conference Abstracts, GSA, Denver Annual Meeting.

[23] Lin, C.W., Hseu, Z.Y., Chen, Z.S. (2002): Clay mineralogy of Spodosols with high clay contents in the subalpine forests of Taiwan. - Clays and Clay Minerals 50: 726-735.

[24] Liu, Z., Alain, T., Clemens, S.C., Wang, P. (2003): Quaternary clay mineralogy in the northern South China Sea (ODP Site 1146). - Science in China Series D: Earth Sciences 46: $1223-1235$.

[25] Merriman, R.J. (2002): Contrasting clay mineral assemblages in British lower Palaeozonic slate belts: the influence of geotectonic setting. - Clay Minerals 37: 207-219.

[26] Meunier, A. (2007): Soil hydroxy-interlayered minerals: a re-interpretation of their crystallochemical properties. - Clays and Clay Minerals 55: 380-388.

[27] Nedachi, Y., Nedachi, M., Bennett, G., Ohmoto, H. (2005): Geochemistry and mineralogy of the 2.45 Ga Pronto paleosols, Ontario, Canada. - Chemical Geology 214: 21-44.

[28] Rich, C.I. (1968): Hydroxy interlayers in expansible layer silicates. - Clays and Clay Minerals 16: 15-30.

[29] Sedov, S., Solleiro-Rebolledo, E., Morales-Puente, P., Arias-Herreìa, A., Vallejo-Gòmez, E., Jasso-Castañeda, C. (2003): Mineral and organic components of the buried paleosols of the Nevado de Toluca, Central Mexico as indicators of paleoenvironments and soil evolution. - Quaternary International 106: 169-184.

[30] Shaw, J.N., Hajek, B.F., Beck, J.M. (2010): Highly weathered mineralogy of select soils from Southeastern US Coastal Plain and Piedmont landscapes. - Geoderma 154: 447-456.

[31] Singer, A. (1980): The Paleoclimatic interpretation of clay minerals in soil and weathering profiles. - Earth Science Reviews 15:303-326.

[32] Singer, A. (1984): The Paleoclimatic interpretation of clay minerals in sediment: a review. 
- Earth Science Reviews 21: 251-293.

[33] Środoń, J. (1999): Nature of mixed-layer clays and mechanisms of their formation and alteration. - Annual Review of Earth and Planetary Sciences 27:19-53.

[34] Toksoy-Koksal, F., Turkmenoglu, A.G., Goncuoglu, M.C. (2001): Vermiculitization of phlogopite in metagabbro, central Turkey. - Clays and Clay Minerals 49: 81-91.

[35] Vali, H., Hesse, R. (1992): Identification of vermiculite by transmission electron microscopy and X-ray diffraction. - Clay Minerals 27: 185-192.

[36] Xie, Q., Chen, T., Zhou, H., Xu, X., Xu, H., Ji, J., Lu, H., Balsam, W. (2013): Mechanism of palygorskite formation in the Red Clay Formation on the Chinese Loess Plateau, northwest China. - Geoderma 192: 39-49.

[37] Xiong, S., Sun, D., Ding, Z. (2002): Aeolian origin of the red earth in southeast China. Journal of Quaternary Science 17: 181-191.

[38] Yang, X., Zhu, Z., Zhang, Y., Li, H., Zhou, W., Yang, J. (2008): Rock magnetic properties and palaeomagnetic results of sediments from a stone implement layer in the Bose Basin, Guangxi. - Science in China Series D: Earth Sciences 51: 441-450.

[39] Yin, K., Hong, H., Churchman, G.J., Li, R., Li, Z., Wang, C., Han, W. (2013): Hydroxy-interlayered vermiculite genesis in Jiujiang late-Pleistocene red earth sediments and significance to climate. - Applied Clay Science 74: 20-27.

[40] Zajzon, N., Kristály, F., Pálfy, J., Németh, T. (2012): Detailed clay mineralogy of the Triassic-Jurassic boundary section at Kendlbachgraben (Northern Calcareous Alps, Austria). - Clay Minerals 47: 177-189.

[41] Zhao, Q., Yang, H. (1995): A preminary study on red earth and changes of Quaternary environment in south China. - Quaternary Sciences 15: 107-116.

[42] Zhu, L. (2007): aggradation red earth sediments in mid-tropics of China and their recorded environment changes during Quaternary. - Lanzhou University (in Chinese). 